\title{
STUDY ON POWER GENERATION BY USING CROSS FLOW WATER TURBINE IN MICRO HYDRO POWER PLANT
}

\author{
S.U.Patel ${ }^{1}$, Prashant.N.Pakale ${ }^{2}$ \\ ${ }^{1}$ Mechanical Engineering Department, D.N.Patel COE shahada-425409, Maharashtra, India \\ ${ }^{2}$ Mechanical Engineering Department, D.N.Patel COE shahada-425409, Maharashtra, India
}

\begin{abstract}
The demand of electricity and fresh water is ever increasing due to increase in population and comfort level of human beings. The micro hydro power is one of the best available solutions as it has economic, social and environmental benefits and is also have a huge potential globally. So this will make demand for micro hydro power generation. The main equipment in micro hydro power generation is turbine. Many turbines are available but among them cross flow water turbine becomes popular as having advantages over using it as in small head and small water flow rate, simple structure and manufacturing method for power generation in hydro power plants. The objective of paper is to review the implementation of cross flow water turbine in Micro hydro power plants (MHP) for power generation.
\end{abstract}

Keywords: Cross flow water turbine, Micro hydro power plant (MHP), power generation. ****

\section{INTRODUCTION TO MICRO HYDRO} \section{POWER PLANT (MHP)}

Hydropower is clean, non-polluting, non-renewable source of energy. It will use the water which will reuse for the other purpose. By moving turbine with the help of water, electricity is produced. It is done by converting kinetic energy and potential energy of water into useful form of energy. It is the oldest technology available for power generation.

Nowdays in $21^{\text {th }}$ century most popular is small scale hydropower i.e. Micro hydro power (MHP). In India, first MHP was of 130 Kilowatt setup in Darjeeling during 1897. For remote areas and environment friendly purpose the small MHP project increasing demand in India.

\subsection{Classification of Hydropower Plants}

Different countries have different norms and conditions for classifying the hydropower plant. In India hydro power project is upto 0.1 Megawatt (MW) capacity have been considered as Micro hydro power plant (MHP). Classification is as follows-

1) Micro hydro power plant $(\mathrm{MHP})=$ upto $0.1 \mathrm{MW}$

2) Mini hydro power plant = upto 0.1 to $2.0 \mathrm{MW}$

3) Small hydro power plant= upto 2.0 to $25 \mathrm{MW}$

4) Large hydro power plant= above $25 \mathrm{MW}$

This power is generated when river or stream is available for enough water. But in small areas there is only one option to establish such type of micro hydro power plant for generation of the electricity.

\subsection{Principle of Micro Power Plant (MHP)}

In power generation from water it uses both head and flow of water. This head will be the difference in water intake and turbine. Water is directed on the turbine with pressure, so that it produces force on the blades of turbine and it drives the generator so as to produce force on the blades of turbine. Then it drives the generator so as to produce electric power. So as flow rate and head increases more will be generation of electricity. This electricity produced always less than that of power input, because of losses due to different reasons.

\section{POWER FROM MICRO HYDROPOWER PLANT}

The power can be calculated from following formula-

$$
\mathrm{P}=\mathrm{Q} \times \mathrm{H} \times \mathrm{e} \times 9.81(\mathrm{KW})
$$

$\mathrm{P}=$ Power at generation or output $(\mathrm{KW})$

$\mathrm{H}=$ The gross head $(\mathrm{m})$

$\mathrm{Q}=$ Flow in pipeline $\left(\mathrm{m}^{3} / \mathrm{sec}\right)$

$\mathrm{e}=$ Efficiency of plant $(\%)$

9.81 is a constant and is product of density of water and acceleration due to gravity $(\mathrm{g})$.

\subsection{Losses in Hydropower Plant}

a) Losses by flow disturbances in pipeline bends and valves

b) Losses by design inefficiencies in turbine and generator.

The turbine efficiencies will ranges from 80 to $95 \%$ generator efficiency will ranges from 90 to $95 \%$. The plant efficiency will ranges from 80 to $85 \%$. 


\section{ADVANTAGES AND DISADVANTAGES OF MHP PLANT}

\subsection{Advantages of Micro Hydro Power Plant}

[1] Clean energy source as do not contain any emission and due to no burning.

[2] Efficient energy source as taken far away as possible.

[3] Reliable electricity source as continuously supplying electric supply.

[4] In power developing countries as having low cost versality and can be used in small, remote and villages.

\subsection{Disadvantages of Micro Hydro Power Plant}

[1] Energy expansion is not possible as depend on size and flow of small streams.

[2] Seasonal variations -as stream of water fluctuates as per season and so effect on plant.

\subsection{Uses of Micro Hydro Power Plant}

Saw mills, carpentry shop, lathe machine, grain grinding etc. can use the power from the MHP plants.

\section{TURBINES USED IN MHP PLANT SYSTEM}

Turbine is main element of hydropower plant that convert energy of falling water into useful rotational work in mechanical form i.e. it will rotates the shaft. Turbine is made of nozzle, stator, runner and shaft. The nozzle will creates high speed jet and runner which converts the hydraulic energy into mechanical power. This runner is attached with cups or blades. This mechanical power is given to the generator by shaft.

\subsection{Types of Turbine}

Turbines are mainly classified into main two types as follows.

\subsubsection{Impulse Turbines}

Impulse turbines generally operate best with medium or high head (above $10 \mathrm{~m}$ ). Penstock of impulse turbine will convert pressurized water into high-speed water jets that transfer the kinetic energy of the jet by impacting the turbine blades or cups causing rotation. The pressure drop in the water flow occurs at the nozzle and the runner operates at atmospheric pressure.

Examples of impulse turbines are Pelton wheel, Turgo wheel and cross-flow water turbine (Banki-Michell).

\subsubsection{Reaction Turbines}

Reaction turbines operate under pressure in an internal flow regime and used for low head range less than $10 \mathrm{~m}$. Water passes the stator, which takes the form of spiral casings or guide vanes, to produce swirl into the flow. The flow is then redirected by the runner blades. The angular momentum of the water forces rotation in the runner. In opposite to impulse turbines, the water pressure drops at the stator and the runner.

Examples of reaction turbines include propeller, Kaplan, and Francis, screw and hydro kinetic turbines (used for low head range less than $10 \mathrm{~m})$.

\subsection{Optimal Selection of Turbine for Hydro Power Plant}

The designer have to choose an optimum turbine type and series, the number of power generating units, the runner diameter, rotational speed, and runner axis elevation. Knowing the total installation at the power station, the number of units can be decided depends on the load requirement of that particular area. The capacity of the plant should be fixed with efficient running, low initial cost, available transport and shipping facilities and should not be so high that turbine would not run at low efficiency at the time of other season. Basically there are two methods which help in selection of turbine are following:

\subsubsection{Thumb Rule}

Different types of turbines can be selected to best suit for given head and flow conditions.

\subsubsection{Scientific Method}

For a particular location and application, initial turbine technology selection should be based on not only technical, but also social, environmental, and economical factors conventionally. Turbines have been mainly selected based on the specific speed. One of the important parameters of a turbine is the Specific Speed denoted as ns, which and defined as the speed in r.p.m. at which a turbine of good design would operate, if the runner were to reduce to a size which would develop one metric horse power under one meter head. It is given by the following relation:

$$
n_{s}=\frac{n \sqrt{P \times 1.358}}{H^{5 / 4}}
$$

Where,

$\mathrm{ns}=$ Specific speed of turbine in revolutions per minute (r.p.m.)

$\mathrm{n}=$ Rated speed of turbine in revolutions per minute

$\mathrm{P}=$ turbine output in $\mathrm{kW}$, and

$\mathrm{H}=$ Rated head in meter.

Once the specific speed (ns) is determined, best suitable turbine can be selected based on this specific speed.

There are more parameters which are taken into consideration-
1) Efficiency
2) Constructability
3) Cost
4) Maintenance and Serviceability
5) Portability 


\section{CROSS FLOW WATER TURBINE (CFWT)}

Nowadays, CFWT is a popular turbine used in micro hydro power plant used for small head range from less than $2 \mathrm{~m}$ to more than $100 \mathrm{~m}$, for small water flow rate and a large variety of flow rates less than $2 \mathrm{MW}$. It is operated with constant diameter runner, by varying the inlet and runner width. CFWT has also advantage that it gets cleaned as water leaves the runner small particles of sand, grass leaves, etc. get washed away due to centrifugal force acted on it. So, prevent the losses in hydropower plant.

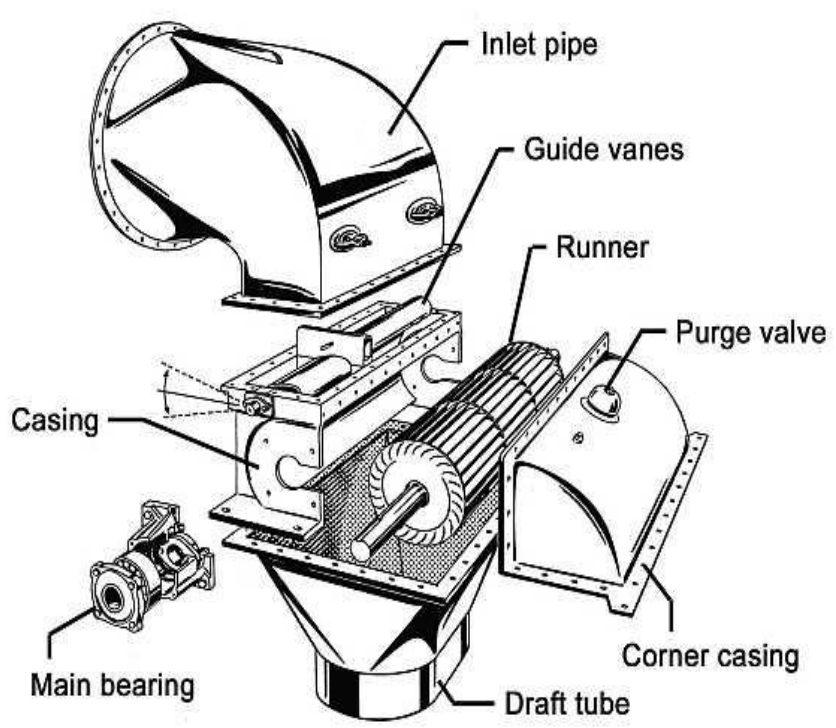

4-(B)

Fig- 1 Cross flow turbine (CFWT).

Cross flow water turbine consist of two component i.e. nozzle and runner. The flow of water crosses the runner blades twice, from outer periphery towards the center of the turbine and after crossing from inside to outside periphery. So this CFWT is with two velocity stages and water filling is only part of the runner. The portion of water cross the runner twice so it is known as crossed flow and turbine is known as cross flow turbine. A nozzle which is in rectangle form, converts potential energy to kinetic energy of water. In CFWT, two surfaces are plane and two are typically curved. CFWT is in the form of cylindrical with two end plates connected by circular array of blades. This CFWT has efficiency about 68 to $70 \%$. In this water is passed twice through runner hence it provides additional efficiency.

The turbine consists of a cylindrical water wheel or runner with a horizontal shaft made up of no. of blades upto 37 arranged radially or tangentially. CFWT has two types 1) Inflow horizontal 2) Inflow vertical.

\subsection{CFWT Advantages over Other Turbines}

[1] No current is required for starting up the project.

[2] Cross flow turbine will continue its efficiency for long period.
[3] There is no cavitation loss with cross flow turbine.

[4] Sufficient with simple lubrication system as no thrust bearing is not used.

[5] Requirement of routine maintenance and needs very small.

[6] Simplicity in design as having two or three moving elements.

[7] CFWT will wash away the grass leaves, sand particles due to centrifugal force acted on it.

[8] Can be used for small range of head $2 \mathrm{~m}$ to $100 \mathrm{~m}$ and for projects with less than $2 \mathrm{MW}$.

\section{CONCLUSION}

Hydropower is a clean source of energy. It does not consume but only uses the water, and after use the water is available for other purposes (although on a lower horizontal level). Cross flow water turbine is used in micro hydro power plant in case of low head and flow rate. This paper gives a complete study of cross flow turbine and necessary fulfill requirement for using in micro hydro power plant. It will helps for selection of turbines to developers to implement CFWT in MHP plants.

\section{REFERENCES}

[1] Bilal Abdullah Nasir, "Design of High Efficiency Cross-Flow Turbine for Hydro-Power Plant" , International Journal of Engineering and Advanced Technology (IJEAT) ISSN: 2249 - 8958, Volume-2, Issue-3, February 2013.

[2] Wakati, R.: "Development of cross-flow turbine for local manufacturing", M. Sc. Thesis, University of Dar Es Salaam, 2010.

[3] Saurabh Sangal, Arpit Garg, Dinesh Kumar, "Review of Optimal Selection of Turbines for Hydroelectric Projects", International Journal of Emerging Technology and Advanced Engineering Volume 3, Issue 3, March 2013).

[4] Muhammad Adil Khan and Saeed Badshah, "Design and Analysis of Cross Flow Turbine for Micro Hydro Power Application using Sewerage Water”, Research Journal of Applied Sciences, Engineering and Technology 8(7): 821-828, 2014

[5] Chiyembekezo S. Kaunda, Cuthbert Z. Kimambo, Torbjorn K. Nielsen, "Experimental study on a simplified cross flow turbine", INTERNATIONAL JOURNAL OF ENERGY AND ENVIRONMENT Volume 5, Issue 2, 2014 pp. 155-182.

[6] Loice Gudukeya, Ignatio Madanhire, "INTERN EFFICIENCY IMPROVEMENT OF PELTON WHEEL AND CROSS FLOW TURBINES IN MICRO-HYDRO POWER PLANTS: CASE STUDY", International Journal Of Engineering And Computer Science ISSN: 2319-7242 Volume 2 Issue 2 Feb 2013 Page No. 416-432.

[7] Anmona Shabnam Pranti, A M Shahed Iqubal, A. Z. A. Saifullah, "Conceptual Design of Solar-micro Hydro Power Plant to Increase Conversion Efficiency for Supporting Remote Tribal Community of Bangladesh", American Journal of Engineering 
Research (AJER) e-ISSN : 2320-0847 p-ISSN :

2320-0936 Volume-03, Issue-11, pp-167-197

\section{BIOGRAPHIES}

Prof. S. U. Patel, Mechanical Engineering Department, D.N.Patel College of Engineering, Shahada-425409, Maharashtra, India.

Email-supatel2004@ rediffmail.com

Prashant N. Pakale, M.E. (Mechanical Engineering)

Student, Mechanical Engineering Department, D.N.Patel College of Engineering, Shahada-425409, Maharashtra, India.

Email-prashantpakale34@gmail.com 